\title{
Indolent IgG4 hypophysitis with partial anterior pituitary failure
}

Seong K Cheah, Singhan M Krishnan, Anitha Mathews, Shyam S Seshadri

Department of Endocrinology and Diabetes, Hinchingbrooke Hospital, North West Anglia Foundation Trust, UK

\section{BACKGROUND}

IgG4 hypophysitis is an increasingly recognised entity causing anterior pituitary failure or diabetes insipidus (1). A series reported underestimation of its prevalence, at $4 \%$ of those with hypopituitarism or diabetes insipidus, with mean age of diagnosis at 62 years old (2). MRI imaging typically revealed pituitary enlargement or stalk thickening (3). In acute or subacute clinical cases presenting with headache and ophthalmological involvement (diplopia or visual field defect), successful treatment with immunosuppressive dose of steroid leading to radiological improvement and resolution of these symptoms $(4,5)$. However, In the lack of agreed guideline in the matter, the necessity of immunosuppressive steroid shall be tailored according to the clinical course. We herein report a case of IgG4 hypophysitis of a more indolent clinical course, which was safely managed conservatively with hormonal replacement for 3 years.

\section{CASE HISTORY}

A 79-year-old man with presented with a fall and vomiting.

The finding of significant postural hypotension associated with severe hypotonic hyponatraemia ( $\mathrm{Na} 114 \mathrm{mmol} / \mathrm{L}$, Osmolarity $244 \mathrm{mmol} / \mathrm{L}$ ) mandated a Short Synacthen Test (cortisol $98 \mathrm{mmol} / \mathrm{L}$ at baseline and $238 \mathrm{mmol} / \mathrm{L}$ 30-minute post synacthen) and ACTH (6ng/L) which confirmed central hypoadrenalism.

This led to revelation of multiple pituitary axes involvement:

- hypogonadism (testosterone $1.1 \mathrm{nmol} / \mathrm{L}, \mathrm{FSH} 1.3 \mathrm{U} / \mathrm{L}, \mathrm{LH} 1.1 \mathrm{U} / \mathrm{L}$ ),

growth hormone deficiency (IGF-1: $5 \mathrm{nmol} / \mathrm{L}$ )

partial central diabetes insipidus confirmed on a water deprivation test.

(The prolactin and thyroid test were normal.)

Confrontation visual field test was unremarkable. The MRI pituitary then revealed a normal pituitary gland with thickened stalk up to $5 \mathrm{~mm}$ (Fig 1). A discussion at pituitary multidisciplinary meeting (MDT) raised suspicion for lymphocytic hypophysitis and led to IgG4 level measurement, which was markedly elevated at $12.7 \mathrm{~g} / \mathrm{L}(0-1.3 \mathrm{~g} / \mathrm{L})$.

Granulomatous infiltration was less likely in this context especially with normal calcium and ACE level. A screening for systemic IgG4 disease with CT thorax and abdomen revealed multiple hilar and mediastinal lymphadenopathy, measuring up to $1.3 \mathrm{~cm}$. These findings were stable on serial imaging which precluded bronchoscopy.

On this ground, a diagnosis of IgG4 related hypophysitis was entertained. In the absence of sight-threatening radiological findings or debilitating symptoms such as headache, high dose steroid was not required as the condition was deemed to be indolent. Patient's symptoms responded to physiological hydrocortisone and testosterone replacement and remained so for the subsequent 3 years of follow-up. Serial annual MRI pituitary consecutively showed nonprogressive findings.
IMAGING

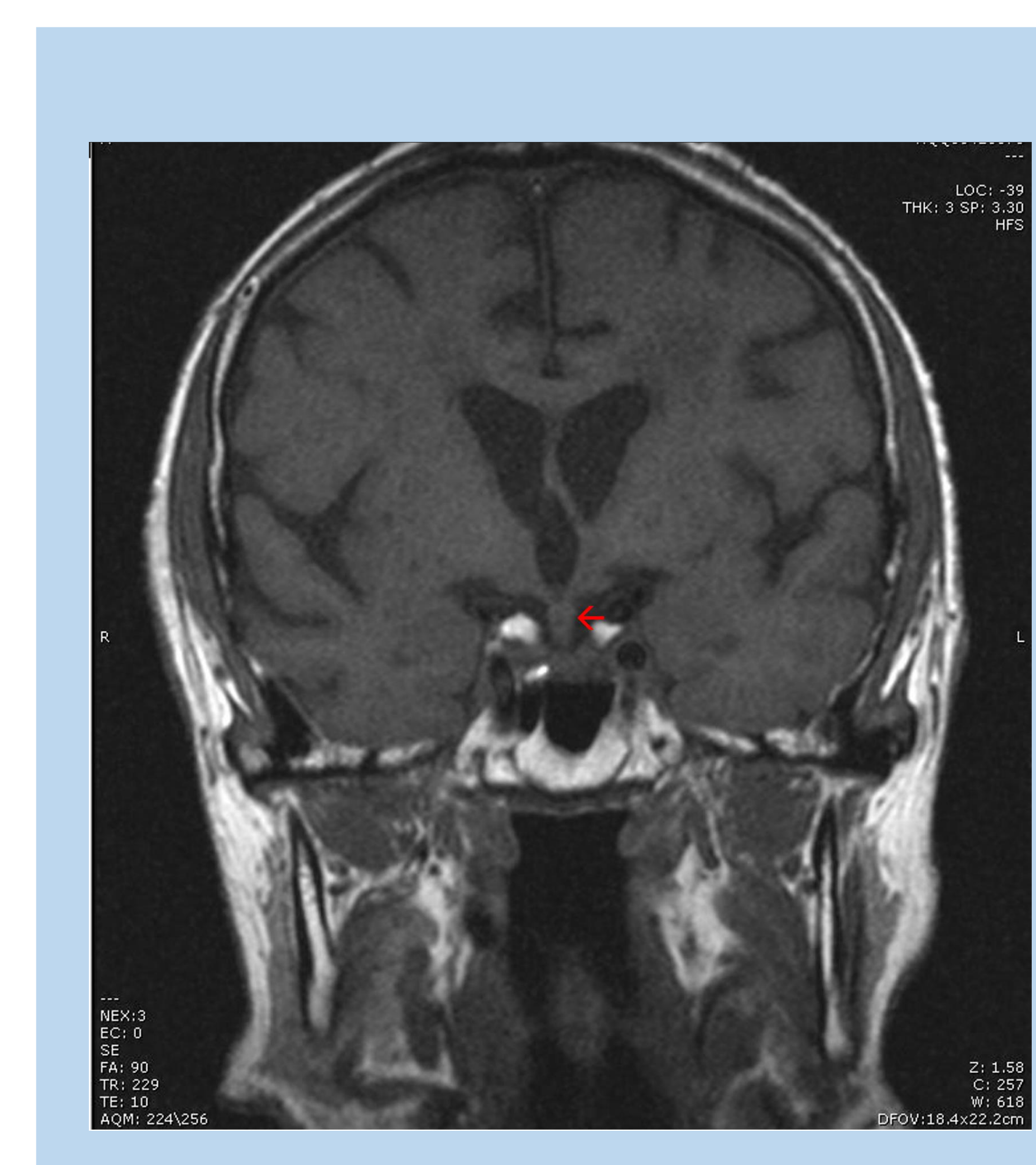

A

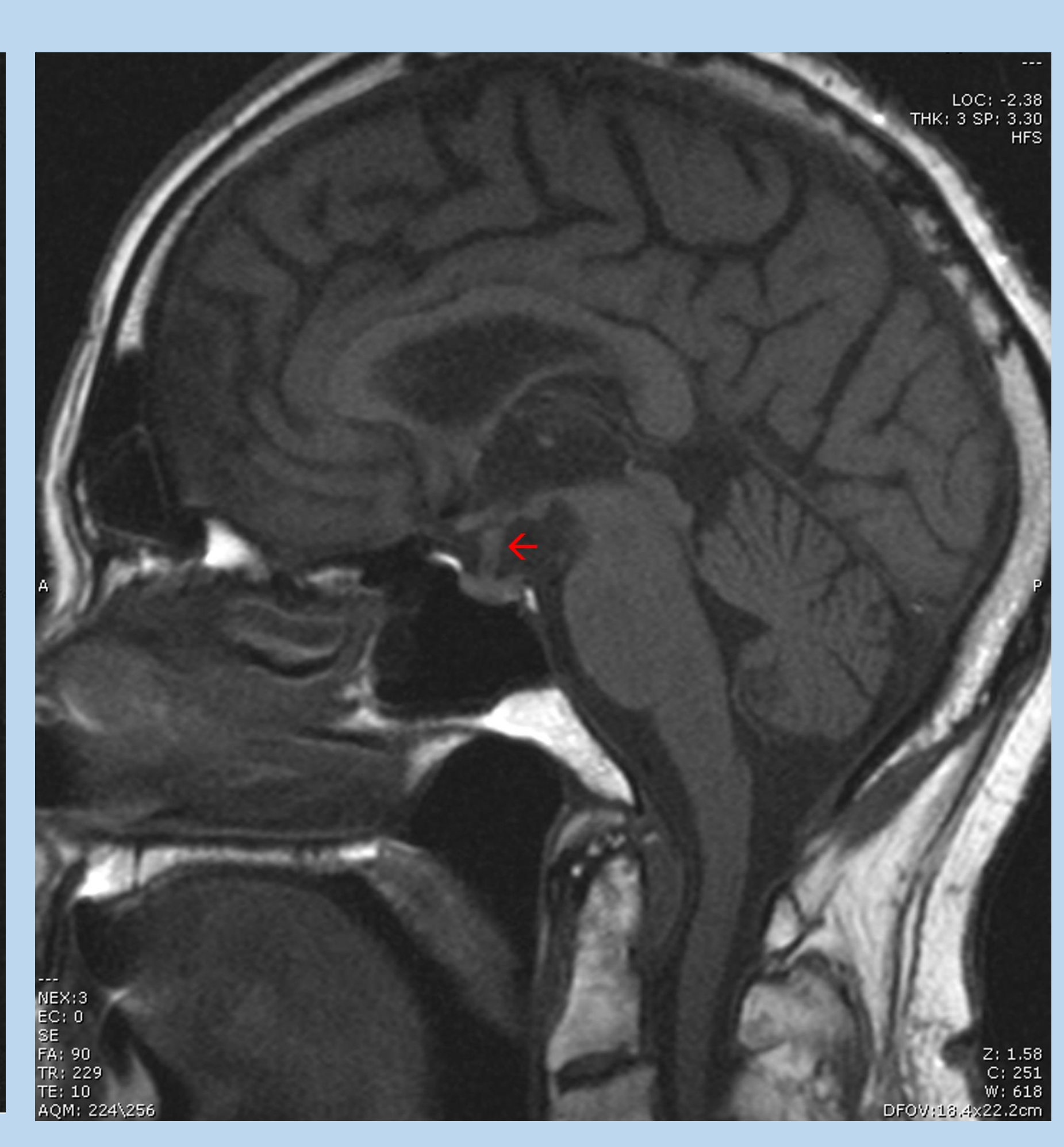

B
Fig 1. MRI brain (T1 sequence) of coronal (A) and sagittal (B) view demonstrating the thickened pituitary stalk (red arrow) with otherwise normal pituitary gland.

\section{CONCLUSION AND LEARNING POINTS}

While acute hypophysitis presenting with florid symptoms or ophthalmological involvement may require high dose steroid, this case presented as indolent "burn-out" disease was safely managed with mere hormonal replacement with no evident progression in the 3 year of follow-up.

Histological confirmation may not be possible or even meaningful in these settings.

\section{REFERENCE}

1. Leporati P, Landek-Salgado MA, Lupi I, Chiovato L, Caturegli P. IgG4-related hypophysitis: a new addition to the hypophysitis spectrum. J Clin Endocrinol Metab. The Endocrine Society; 2011 Jul;96(7):1971-80.

2. Bando H, Iguchi G, Fukuoka H, Taniguchi M, Yamamoto M, Matsumoto R, et al. The prevalence of IgG4-related hypophysitis in 170 consecutive patients with hypopituitarism and/or central diabetes insipidus and review of the literature. Eur J Endocrinol. European Society of Endocrinology; 2014 Feb 1;170(2):161-72.

3. SHIMATSU A, OKI Y, FUJISAWA I, SANO T. Pituitary and Stalk Lesions (Infundibulohypophysitis) Associated with Immunoglobulin G4-related Systemic Disease: an Emerging Clinical Entity. Endocr J. The Japan Endocrine Society; 2009;56(9):103341.

4. Byrne TN, Stone JH, Pillai SS, Rapalino O, Deshpande V. Case 31-2016. Cabot RC, Rosenberg ES, Harris NL, Shepard J-AO, Cort AM, Ebeling SH, et al., editors. N Engl J Med. Massachusetts Medical Society; 2016 Oct 13;375(15):1469-80.

5. Hattori Y, Tahara S, Ishii Y, Kitamura T, Inomoto C, Osamura RY, et al. A Case of IgG4-Related Hypophysitis Without Pituitary Insufficiency. J Clin Endocrinol Metab. Oxford University Press; 2013 May 1;98(5):1808-11. 